This item was submitted to Loughborough's Research Repository by the author.

Items in Figshare are protected by copyright, with all rights reserved, unless otherwise indicated.

\title{
The torsional waveguide viscosity probe: design and anomalous behavior
}

\section{PLEASE CITE THE PUBLISHED VERSION}

http://dx.doi.org/10.1109/TUFFC.2011.1990

PUBLISHER

(c) IEEE

\section{VERSION}

AM (Accepted Manuscript)

\section{LICENCE}

CC BY-NC-ND 4.0

\section{REPOSITORY RECORD}

Rabani, Amir, Richard E. Challis, and Valerie J. Pinfield. 2012. "The Torsional Waveguide Viscosity Probe: Design and Anomalous Behavior”. figshare. https://hdl.handle.net/2134/11090. 
This item was submitted to Loughborough's Institutional Repository (https://dspace.lboro.ac.uk/) by the author and is made available under the following Creative Commons Licence conditions.

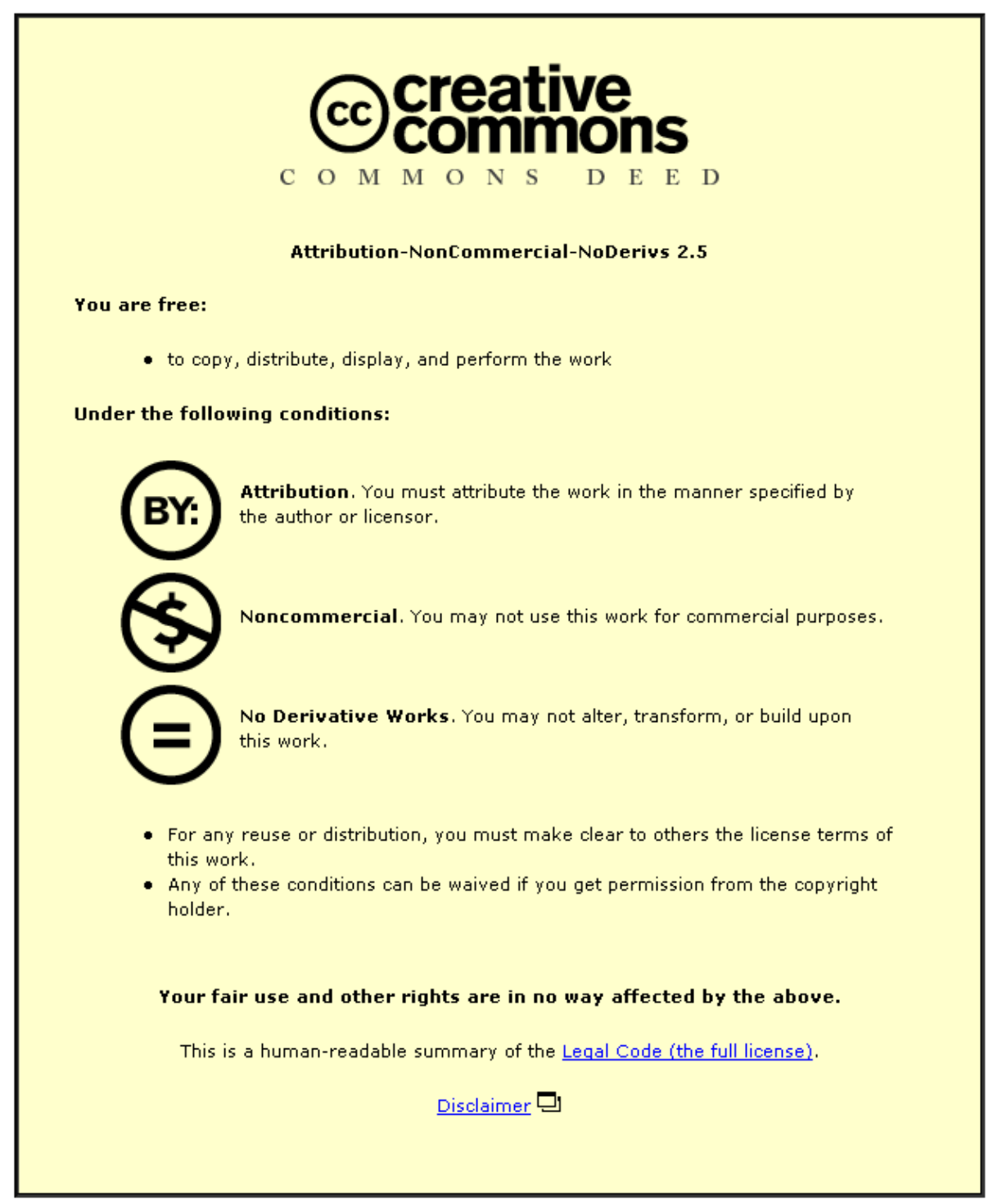

For the full text of this licence, please go to: http://creativecommons.org/licenses/by-nc-nd/2.5/ 


\title{
THE TORSIONAL WAVEGUIDE VISCOSITY PROBE: DESIGN AND ANOMALOUS BEHAVIOUR
}

Amir Rabani, Richard E. Challis and Valerie J. Pinfield

Electrical Systems and Optics Division, Faculty of Engineering, University of Nottingham, NG7 2RD, UK.

Correspondence to: eexar5@nottingham.ac.uk

Key words: Ultrasonic torsional waveguide, viscosity probe.

\begin{abstract}
This paper is concerned with the design of viscosity sensors based on a torsional waveguide. The advantages of using guided wave attenuation instead of speed for viscosity estimation are established. The effects of probe material, dimensions and operating frequency on viscosity measurement are discussed in the context of a requirement to match the measured attenuation to the range of viscosity values that are required to be measured, given the constraints on measurability imposed by the overall signal and noise conditions. A prototype probe is shown to work well with Newtonian liquids but to appreciably underestimate the viscosities of polymeric oils; these anomalies are explained quantitatively on the basis of a model of intramolecular relaxation. The probe was unsuccessful when applied to slurries, and a basic explanation is given.
\end{abstract}

\section{INTRODUCTION}

Ultrasonic guided wave probes can be used to measure viscosity and/or density in liquids [1-9]. They can be formed into robust instruments which are inexpensive enough to be disposable when applied to hazardous materials, or can be used on-line in a process. They have advantages over 
conventional rotating element rheometers which are delicate, expensive, and not suitable for operation in a process line. In operation a rod, usually of metal, is immersed in the liquid to be tested, Fig. 1. Transducers excite guided waves at one end of the rod and these travel along the rod and are reflected back to the transducer either from the end of the rod or from an embedded discontinuity part way down. The echoes thus received are amplified and processed to extract the propagation velocity and/or the attenuation of the waves in the rod.

Both velocity and attenuation are affected by coupling between the motions of the rod surface associated with the propagating wave in the rod and motions in the liquid in contact with the rod. Under the common condition that phase speed within the rod is greater than the speed of viscous waves in the surrounding fluid, such coupling will cause radiation of energy into the fluid, reducing both speed and amplitude of the guided wave.

Thus, depending on the guided wave mode either the attenuation or the velocity can be used to calculate the viscosity or the density of the surrounding liquid. The group velocity dispersion curves for guided waves in a free (in vacuo) carbon steel rod, calculated using the Disperse software package [10], are shown on Fig. 2. For a rod of $1 \mathrm{~mm}$ diameter, below $1.8 \mathrm{MHz}$ there are three principal modes - longitudinal $\mathrm{L}(0,1)$, torsional $\mathrm{T}(0,1)$, and flexural $\mathrm{F}(1,1)$. The wave naming convention here is based on Silk and Bainton [11]. The torsional mode is the most sensitive to viscosity and will form the basis of further discussion in this paper.

Measurements made with conventional rheometers and guided wave probes have been compared in a number of works. When testing Canon viscosity standards [12] with a guided wave probe operating in the $50 \mathrm{kHz}-100 \mathrm{kHz}$ range Kim and Bau [4], Costley et al [6] and Vogt et al [8] showed that the two techniques agreed well, although Ai and Lange [9] did not find good agreement in the higher frequency range $300 \mathrm{kHz}-400 \mathrm{kHz}$. Similarly, Shepard et al [7] were unsuccessful in measuring Brookfield viscosity standards [13] in the frequency range $50 \mathrm{kHz}$ - 
$100 \mathrm{kHz}$, although they were successful in measuring the viscosities of automotive engine oils. Simpler liquids such as glycerol/water mixtures gave successful comparisons [7-8]. An example of high temperature operation was demonstrated by Costley et al [6] who measured the viscosity of molten glass. Finally, Shepard et al [7] were unsuccessful in measuring the viscosity of slurry materials. It would thus appear that the guided wave viscosity probe can measure the viscosity of certain liquids but not others. The answer to this probably lies in the design of the probe and its operating protocol, the details of which were not discussed in any depth in the works cited so far.

In this paper we address a number of basic but important issues associated with the design of guided wave viscosity probes. These are: choice of transduction system, the relative advantages of using attenuation or propagation velocity as the basis for viscosity calculation, the choice of waveguide material, diameter and length, and choice of operating frequency. We then present a basic design study and a simple prototype probe for which we validate generation of the $T(0,1)$ mode. Successful operation is demonstrated on a range of relatively simple Newtonian liquids. Tests on non-Newtonian liquids highlight anomalies similar to those found in $[7,9]$ and these are investigated and explained for a group of silicone oils of the type used as viscosity standards. The probe was not able to measure the viscosities of bulk slurries.

\section{THEORETICAL BASIS}

We consider guided wave propagation in a solid cylindrical rod with a length much greater than its diameter. We assume that the properties of the fluid are stationary in time and space, that all deformations are small enough to maintain linear responses, that the waveguide is axisymmetrical, and that the zero-slip condition applies between the rod surface and the surrounding liquid. The rod has radius $r$, density $\rho_{\mathrm{s}}$ and shear modulus $\mu$; it is embedded in a liquid of density $\rho_{\mathrm{f}}$ and viscosity $\eta$. Kim and Bau [4] derived the following expressions for the attenuation and speed of the $\mathrm{T}(0,1)$ mode at angular frequency $\omega$ under the above conditions as 
$\alpha=\rho\left(\frac{2 \omega}{c_{s} r R e}\right)^{1 / 2}+\frac{\left(\omega^{2} r^{2}-6 c_{s}^{2}\right) p^{2}+9 c_{s}^{2} \rho}{3 c_{s}^{2} r R e}+O\left(\frac{1}{\operatorname{Re}^{3 / 2}}\right)$

$c=c_{s}-c_{s} \rho\left(\frac{2 c_{s}}{r \omega \mathrm{Re}}\right)^{1 / 2}\left[1-\rho\left(\frac{2 c_{s}}{r \omega \mathrm{Re}}\right)^{1 / 2}\right]+\mathrm{O}\left(\frac{1}{\mathrm{Re}^{3 / 2}}\right)$

where, $c_{s}$ is the torsional wave speed or the bulk shear speed in a free waveguide and is given by $c_{s}=\left(\mu / \rho_{s}\right)^{1 / 2}$. Here $\rho$ is the non-dimensional density, $\rho=\rho_{f} / \rho_{s}$ and Re the characteristic

Reynolds number, $\mathrm{Re}=\rho_{f} r c_{s} / \eta$. In eqs. (1-2), higher order terms, $\mathrm{O}\left(1 / \mathrm{Re}^{3 / 2}\right)$, corresponding to the curvature of the cylinder, can be neglected for large Re as the radius of the cylinder is usually much larger than the thickness of the viscous boundary layer. We can rewrite eqs. (1-2) by substituting the equivalent term for Re, and terminating the series by omitting higher order terms

$\alpha=\frac{\rho}{c_{s} r}\left(\frac{2 \omega \eta}{\rho_{f}}\right)^{1 / 2}+\frac{\eta\left[\left(\omega^{2} r^{2}-6 c_{s}^{2}\right) \rho^{2}+9 c_{s}^{2} \rho\right]}{3 c_{s}^{3} r^{2} \rho_{f}}$

$c=c_{s}-\frac{c_{s} \rho}{r}\left(\frac{2 \eta}{\omega \rho_{f}}\right)^{1 / 2}\left[1-\frac{\rho}{r}\left(\frac{2 \eta}{\omega \rho_{f}}\right)^{1 / 2}\right]$

These equations will be used to investigate probe design in the sections of this paper which follow.

\section{PROBE DESIGN CONSIDERATIONS}

\section{A. Attenuation Versus Wave Velocity for Viscosity Estimation}

It is clear from the above that either attenuation or velocity could be used for viscosity measurement. Velocity has been used in [4, 7] and attenuation in [5, 8, 9]. The choice between these two must lie in the relative sensitivity of errors in the viscosity calculation to errors in the 
raw attenuation or velocity data, combined with the technical difficulty of containing errors in the two raw measurements. Error propagation can be quantified by taking two differentials:

$$
\begin{aligned}
& \Delta \eta \approx \frac{\partial \eta}{\partial \alpha} \Delta \alpha \\
& \Delta \eta \approx \frac{\partial \eta}{\partial c} \Delta c
\end{aligned}
$$

Taking the derivatives of eqs. (3-4) we obtain

$$
\begin{aligned}
& \left|\frac{\Delta \eta}{\eta}\right| \approx\left|\frac{6 \alpha \rho_{f} c_{s}^{3} r^{2}}{3 c_{s}^{2} r \rho\left(2 \eta \omega \rho_{f}\right)^{1 / 2}+2 \rho^{2} \eta\left(\omega^{2} r^{2}-6 c_{s}^{2}\right)+18 c_{s}^{2} \rho \eta}\right| \frac{\Delta \alpha}{\alpha} \mid \\
& \left|\frac{\Delta \eta}{\eta}\right| \approx\left|\frac{2 c \rho_{f} r^{2} \omega}{-c_{s} \rho r\left(2 \eta \rho_{f} \omega\right)^{1 / 2}+4 c_{s} \rho^{2} \eta}\right| \frac{\Delta c}{c} \mid
\end{aligned}
$$

The relative viscosity error thus depends on the viscosity being measured and the properties of the waveguide rod. Let us assume that we require a relative viscosity error of no greater than $1 \%$ when using a waveguide of $1 \mathrm{~mm}$ diameter carbon steel (see Table 1) embedded in a liquid of density equal that of olive oil $\left(913 \mathrm{kgm}^{-3}\right)$ and that we have a choice of operating frequencies in the range $50 \mathrm{kHz}$ to $800 \mathrm{kHz}$. Figs. 3 and 4 show the relative errors in attenuation and velocity that would be required to achieve $1 \%$ accuracy in viscosity over the range 0 to 2 Pa.s. We note that the required accuracy in attenuation at 2 Pa.s is of the order of $0.5 \%$, being slightly greater at the lowest frequency. The required relative velocity error at 2 Pa.s varies between $1.1 \times 10^{-3} \%$ and $4.3 \times 10^{-3} \%$, again increasing as frequency reduces. The velocity of $\mathrm{T}(0,1)$ is $3178 \mathrm{~ms}^{-1}$; if the length of the waveguide is $0.1 \mathrm{~m}$ the travelling wave propagation time which is to be measured will be $62.9 \mu \mathrm{s}$, giving a limit to the timing error of $0.629 \mathrm{~ns}$. Technically, it would be very 
difficult to achieve such accuracy in typical electronic systems where the wave period is of the order of $1 \mu$ s or more.

On the other hand, an error of $0.5 \%$ in an attenuation measurement is achievable, although not easy. We note here that measurements of attenuation are more sensitive to viscosity because the attenuation is dominated by the embedding fluid properties whereas velocity is principally determined by the waveguide properties. We therefore conclude that measurements of attenuation are to be preferred over velocity as the basis for viscosity estimation with a torsional wave probe. The relationship between attenuation and viscosity is obtained by re-arranging eq. (3) to get the following explicit expression

$$
\eta\left[\frac{\left(\omega^{2} r^{2}-6 c_{s}^{2}\right) \rho+9 c_{s}^{2}}{3 \rho_{s} c_{s}^{3} r^{2}}\right]+\eta^{1 / 2}\left[\frac{1}{\rho_{s} c_{s} r}\left(2 \rho_{f} \omega\right)^{1 / 2}\right]-\alpha=0
$$

Eq. (9) is a second order polynomial equation in $\eta^{1 / 2}$ and has two roots of which one is complex. Taking the real root, the viscosity for a given attenuation, angular frequency and density is given by

$$
\eta=\frac{3 c_{s}^{2} r^{2}}{2}\left[\frac{-c_{s}\left(3 \omega \rho_{f}\right)^{1 / 2}+\left(3 \omega \rho_{f} c_{s}^{2}+2 \alpha \rho_{s} c_{s}\left[\left(\omega^{2} r^{2}-6 c_{s}^{2}\right) \rho+9 c_{s}^{2}\right]\right)^{1 / 2}}{\left(\omega^{2} r^{2}-6 c_{s}^{2}\right) \rho+9 c_{s}^{2}}\right]^{2}
$$

This explicit expression enables viscosity in a fluid of known density to be calculated at a given frequency from the measured attenuation of the fundamental torsional mode $\mathrm{T}(0,1)$ in a long, thin, solid rod of circular cross-section.

\section{B. Choice of Transduction System}

There are three ways to implement transducers for the excitation and reception of guided waves in the rod. Magnetostrictive devices have been used by Kim and Bau [4], Costley et al [5], 
Shepard et al [7] and Vogt et al [8]. Such devices are relatively large and require that the probe rod, or a section of it, is formed of magnetostrictive material. This limits the choice of material and increases both cost and complexity of construction. EMAT devices have been used by Ai and Lange [9]; they are relatively expensive and less sensitive than magnetostrictive devices. The third method is the piezoelectric shear plate which has the significant advantages of low cost, small size, high sensitivity and ease of mounting and probe construction. It is therefore our preferred means of transduction.

\section{Waveguide Material}

The sensitivity of torsional wave attenuation to viscosity depends on the material from which the waveguide is formed, through density and shear modulus. We show on Fig. 5 attenuation versus viscosity calculated from eq. (10) for the eight metals identified in table 1 . It is clear that the lower density and lower shear modulus materials exhibit the greatest sensitivity, particularly so in the case of aluminium on Fig. 5. The choice of material should therefore be made taking account of both the range of viscosities to be measured and the value of attenuation that is measurable, a complex topic which is discussed later.

\section{Probe Diameter}

The probe diameter affects sensitivity to viscosity, again through eq. (10). We illustrate this for carbon steel rods of diameters $1 \mathrm{~mm}, 2 \mathrm{~mm}$ and $3 \mathrm{~mm}$ operating at $600 \mathrm{kHz}$ on Fig. 6, from which it is clear that sensitivity increases rapidly as diameter is reduced. So, given a chosen material, the diameter should be set in relation to the expected viscosity values and the range of attenuation that is measurable, as before. 


\section{E. Probe Length}

The length of the probe rod is determined by the combination of the physical requirements of the measuring system, such as accessibility, and the expected total measured loss which is twice the product of the wave attenuation coefficient and the probe length, usually expressed in $\mathrm{Np}$ or $\mathrm{dB}$. In any measurement the attenuation is calculated from the frequency domain relationship

$$
\alpha(\omega)=\frac{1}{2 l} \ln \frac{X_{C A L}(\omega)}{X(\omega)}
$$

where $l$ is the probe length, and $X_{C A L}(\omega)$ and $X(\omega)$ are the frequency domain amplitudes of the received guided wave in vacuo and in the test liquid respectively. Kalashnikov and Challis [14] have shown that errors due to variance or bias in $X(\omega)$ map non-linearly into errors in $\alpha(\omega)$. The optimum condition for minimum error in attenuation is when the total measured loss, $2 l \alpha(\omega)$ is 1 Np. At higher attenuations the errors worsen as $X(\omega)$ diminishes in relation to the system noise and here the practical limit is a total measured loss of between $3 \mathrm{~Np}$ and $5 \mathrm{~Np}$. There is a lower limit to measurable loss which arises from the problem of discerning small changes in signals of relatively high amplitude, and this is shown in [14] to be around $0.5 \mathrm{~Np}$. The implication of this for probe design is that, for a given material, diameter and operating frequency (discussed below) the probe length should be such that the attenuation expected at the mid range of the viscosities to be measured should give a total measured loss of around $1 \mathrm{~Np}$, with the further constraint that the range of expected viscosities should not bring about a measured loss outside of the range 0.5 Np to 5 Np.

Notwithstanding these conditions, it may be necessary to employ a long probe for access reasons. If this were to lead to excessively high attenuation then the problem can be overcome by immersing only part of the probe length into the liquid under test. There will be extra echoes from the discontinuity at the fluid surface, but these are generally of relatively low amplitude and 
easy to gate out. The small change in signal received from the distal end of the probe is generally insignificant. Ai and Lang [9] reported 4\% - 6\% change in reflection coefficient from the embedded distal end of the molybdenum probe with $1 \mathrm{~cm}$ diameter compare to the rod in air for liquids with viscosity of the order of 5000 Pa.s. However this change is many times lower in magnitude for liquids with lower viscosities and rods with smaller diameters as used in this study.

\section{F. Operating Frequency}

In principle, shearing piezoelectric transducers, if themselves perfect, and if perfectly attached to the probe rod, should excite only a torsional mode. However, such perfection is difficult to achieve in practice and some energy will exist in non-torsional modes such as $\mathrm{L}(0,1)$ and $\mathrm{F}(1,1)$ in Fig. 2, for example. It is therefore necessary that the frequency-diameter product be such that the required torsional mode travels at a speed that is significantly different from that of the unwanted modes - in order to allow time gating of the torsional signal for further processing. Referring to Fig. 2, this would require an operating frequency well below $1 \mathrm{MHz}$ for the $1 \mathrm{~mm}$ diameter steel probe. If the diameter was doubled this limit would halve.

The sensitivity to viscosity increases with frequency, Fig. 7, calculated from eq. (3). Whilst the effect of frequency on sensitivity is not particularly strong - 36\% increase in sensitivity for 300\% increase in frequency - it may nevertheless be necessary to take it into account if the measurement conditions approach the limits of maximum or minimum measurable loss.

\section{DESIGN EXAMPLES}

\section{A. General Purpose Experimental Probe}

The requirement was to support the experiments which are described later in this paper. The transducers were to be distanced from the test liquid by between $75 \mathrm{~cm}$ and $95 \mathrm{~cm}$, the gauge length at the distal end of the probe being adjustable between $5 \mathrm{~cm}$ and $25 \mathrm{~cm}$. Taking the 
maximum, optimum and minimum values of measurable loss as $5 \mathrm{~Np}, 1 \mathrm{~Np}$ and $0.5 \mathrm{~Np}$ respectively, these conditions gave a range of measurable attenuations between $1 \mathrm{Npm}^{-1}$ and 50 $\mathrm{Npm}^{-1}$ with the optima between $2 \mathrm{Npm}^{-1}$ and $10 \mathrm{Npm}^{-1}$. From Fig. 5, for a $1 \mathrm{~mm}$ diameter steel probe these attenuations are equivalent to viscosities ranging from less than 0.1 Pa.s up to around 30 Pa.s at $600 \mathrm{kHz}$. The detailed construction of this probe will be described after the second design example.

\section{B. Compact Probe for Automotive Use}

Another example of the torsional waveguide probe application is to monitor the viscosity of automotive oils in automotive engines. In this case the probe needs to be compact and fully immersed in the liquid. The entire probe rod forms the gauge length; therefore, the length of the probe rod is crucial. The material of the probe should be selected so as to provide the maximum sensitivity for the required viscosity range, which for automotive oils is normally between 0.1 Pa.s and 1 Pa.s. For example, choosing aluminium as the probe rod material for a $1 \mathrm{~mm}$ diameter probe we have a range of attenuation between $6.4 \mathrm{Npm}^{-1}$ to $20.9 \mathrm{Npm}^{-1}$ (Fig. 5). Taking the maximum, optimum and minimum values of measurable loss as $5 \mathrm{~Np}, 1 \mathrm{~Np}$ and $0.5 \mathrm{~Np}$ respectively, these conditions gave a range of gauge lengths with maxima between $12 \mathrm{~cm}$ and 39 $\mathrm{cm}$, with minima between $1.2 \mathrm{~cm}$ and $3.9 \mathrm{~cm}$ and with optima between $2.4 \mathrm{~cm}$ and $7.8 \mathrm{~cm}$. A single probe which is capable of measuring over the required viscosity range would have a length in the range $3.9-7.8 \mathrm{~cm}$.

\section{CONSTRUCTION OF EXPERIMENTAL PROBE}

A set of six carbon steel probes have been built, Fig. 8. The transducer devices were piezoelectric shear plates of PIC 255 material (PI Ceramic GmbH, Lederhose, Germany) of dimensions 3.0 $\mathrm{mm} \times 2.0 \mathrm{~mm} \times 0.2 \mathrm{~mm}$ and poled so as to vibrate transversely. Their long faces have sputtered CuNi electrodes. The shear plates are bonded to the rod using a conductive epoxy (CW2400, 
Circuitworks, Kennesaw, USA). To provide robustness the whole assembly is encapsulated in general purpose epoxy polymer (Double-Bubble, Bondmaster, Eastleigh, UK) contained within a short segment of PVC pipe. The general arrangement is shown in Fig. 9.

\section{VALIDATION OF WAVE MODES}

The probe was mounted in air, with no fluid loading. A WaveMaker Duet instrument (OrrCam Design Ltd, London, UK) was used to excite the transducers with a zero integral pulse. The guided waves so generated travel to the far end of the rod and are reflected back to the transducers where they are received by the same WaveMaker instrument and amplified by up to $40 \mathrm{~dB}$.

A digital oscilloscope (DSO, LeCroy 9314CM, New York, USA) was used to digitize the analogue received signal; it communicated with a PC by a GPIB interface (IEEE 488). The echoes received from the distal end of the rod were analysed by the time-frequency spectrogram method [15-17] which provides a means to separate multiple echoes in time whilst at the same time displaying their frequency content. The received signal train is decimated into windowed segments in the time domain, each of length $25.6 \mu$ s with $25.5 \mu$ s overlap. Successive windowed records are transformed to the frequency domain by FFT and then these functions are shown as a combination plot versus time. Fig. 10 shows the result for the $1 \mathrm{~mm}$ waveguide -the presence of $T(0,1), L(0,1)$ and $F(1,1)$ is clear, with $L(0,1)$ and $F(1,1)$ being of significantly lower intensity.

It is interesting to examine the fate of these modes when the probe is immersed. Fig 11 shows the equivalent spectrogram when the probe is immersed in water, and here we see that $F(1,1)$ disappears, because it is anti-symmetrical and such modes are extremely weak in an axisymmetrical waveguide excited by a symmetrical pair of transducers. However, $L(0,1)$ is a symmetrical mode and remains strong on Fig. 11. Thus when a probe is in use to measure viscosity it will be necessary to window out the longitudinal mode but not the flexural one. 
As a preliminary test of the ability of the probe to detect the viscosity of an embedding liquid we measured torsional wave attenuation when the probe was immersed in a solution consisting of $80 \%$ w/w Golden Syrup (Tate \& Lyle, Nottingham, UK) in water at nine frequencies in the range 525 $\mathrm{kHz}$ to $725 \mathrm{kHz}$. For each measurement viscosity was calculated from eq. (10) and the average of these viscosities was used in eq. (3) to calculate the expected attenuation versus frequency. The results are plotted in Fig. 12 which shows reasonable agreement between the raw attenuation data and the calculated curve.

\section{MEASUREMENTS ON LIQUIDS}

Whilst a probe in use in a real application would operate at a single defined immersion depth we have developed a system with which the immersion depth can be adjusted; it is based on [18]. The apparatus is shown on Fig. 13. A graduated glass cylinder was used as a container for the test liquid and the waveguide inserted vertically from the top. The cylinder was set inside a water bath (SUB Aqua 5L, Grant Instruments Ltd, Cambridge, UK) which maintained the temperature of the test fluid in the range $20-24{ }^{\circ} \mathrm{C} \pm 1.5{ }^{\circ} \mathrm{C}$. The immersion depth was set by means of a supporting table whose height could be adjusted by a 'scissors' screw jack. A thermocouple data logger (TC -08, Pico Technology Limited, St Neots, UK) with standard type K thermocouples were used for temperature measurements. In order to measure the guided wave attenuation in the rod the immersion depth was successively increased and the echo signals from the end of the rod were recorded for each depth. These diminish in amplitude as the immersion depth is increased due to the attenuating effect of the surrounding liquid. At each depth, $x$, the recorded timedomain signal $s(\mathrm{x}, t)$ is transformed into the frequency domain by FFT. 10 cycle tone-burst signals were used at different frequencies in the range $525-725 \mathrm{kHz}$, and the received signals were digitised at $50 \mathrm{MHz}$. Frequency domain signal amplitudes at any frequency, $S(x, f)$, can be processed in a number of different ways to compute the guided wave attenuation coefficient. The 
simplest option is to take two immersion depths $x_{1}<x_{2}$ and calculate the attenuation coefficient using the frequency domain signals at these depths. Thus:

$$
\alpha(f)=\frac{1}{2\left(x_{2}-x_{1}\right)} \ln \left|\frac{S\left(x_{1}, f\right)}{S\left(x_{2}, f\right)}\right|
$$

The calculated attenuation coefficient is used to determine the viscosity using eq. (10). The immersion depth was set so as to bring the measured loss as close as possible to $1 \mathrm{~Np}$. In the viscosity calculations the density of both the waveguide and the liquid are assumed to be known. The variation in the attenuation measurements, calculated as a standard deviation over eight recordings, is around $\pm 0.5 \%$. The density of the test liquid is measured by determining the weight of a known volume of liquid to an accuracy of $\pm 1 \%$. The uncertainty in the measured temperature is $\pm 1.5^{\circ} \mathrm{C}$, within the specification of the $\mathrm{K}$ type thermocouple used. All measurements were performed at temperatures between 20 and $24^{\circ} \mathrm{C}$.

Viscosity measurements with the guided wave probe were done at $25 \mathrm{kHz}$ intervals in the range $550 \mathrm{kHz}$ to $725 \mathrm{kHz}$, giving eight readings in all. The standard deviations of each group of eight readings were less than or equal to $3.8 \%$. The mean of each group of eight readings was taken as the measured viscosity. For each test liquid, reference measurements were done for comparison purposes using a conventional rotating element rheometer operating in steady shear mode (Physica MCR 301, Anton Paar GmbH, Graz, Austria) with cone and plane (spindle: CP-50) for the liquids and starch stirrer and cup (spindle: ST-24) for slurries. The maximum error associated with this system is $\pm 2 \%$. A total of 31 measurements were made on each liquid at shear rates ranging from 0 to $1000 \mathrm{~s}^{-1}$. Over all tests these data exhibited maximum standard deviations of 3\% or less, indicating that dependence on shear rate was negligible for the liquids used. For each liquid the value of viscosity used was the average of the 31 readings. 


\section{A. Test Liquids}

Various liquids were employed to compare viscosity measurements using the torsional waveguide probe with those from the conventional rheometer. They included sunflower oil and olive oil, castor oil, glycerol/water mixtures, golden syrup/water mixtures, automotive engine and gearbox oils, and silicone oils which are often used as viscosity standards. In addition, slurries made of mixtures of two different magnesium hydroxides with particle diameters ranging from $0.055 \mu \mathrm{m}$ to $2.36 \mathrm{~mm}$ with water or glycerol as the continuous phase were tested. The details of these materials are given in Table 2.

The simpler liquids in Table 2 were expected to exhibit Newtonian behaviour. The silicone oils and the engine and gear oils were expected to exhibit non-Newtonian behaviour at higher frequencies and possibly at higher shear rates [19-22]. The viscosity of slurries is also known to be shear rate dependent and other effects are likely due to the high frequencies used in the torsional probe.

\section{EXPERIMENTAL RESULTS: NEWTONIAN LIQUIDS}

The densities and viscosities of the Newtonian liquids measured by the two methods are summarised in Table 3. All viscosities obtained with the conventional rheometer were independent of shear rate. The two methods are compared graphically in Fig. 14. The results show good agreement between the two methods, the differences ranging between $1.0 \%$ and $8.4 \%$ - except for water where the error was 33.3\%.The reason for this is that the attenuation measured in water was very low $\left(0.25 \mathrm{Npm}^{-1}\right)$ and below the lower measurable limit of $1 \mathrm{Npm}^{-1}$ discussed earlier. 


\section{EXPERIMENTAL RESULTS: NON-NEWTONIAN LIQUIDS}

The densities and viscosities of the non-Newtonian liquids measured by the two methods are summarised in Table 4. The viscosities were measured over the same frequency range as before but the individual values were not averaged because frequency dependent behaviour was expected. For comparison with the results from the conventional rheometer the viscosity measured with the guided wave probe at $625 \mathrm{kHz}$ was used. The results are given in Table 4 and are shown graphically on Fig. 15. It is clear that there are significant differences between the two sets of results, the values measured by the torsional waveguide probe differing by up to a factor of six from those measured by the conventional rheometer. This apparently anomalous behaviour has been reported previously by Shepard et al. [7] for silicone oils using a torsional wave speed method to measure viscosity; the authors did not offer any quantitative explanation for their unexpected results.

\section{A. Explanation of Anomalous Behaviour}

It is most likely that the anomalous behaviour reported above results from either the high operating frequency of the guided wave probe, or the possibility of different shear rates associated with the two techniques. We estimate the shear rates associated with the guided wave probe to be around $5000 \mathrm{~s}^{-1}$ at $625 \mathrm{kHz}$ for water (lower for more viscous liquids), of the same order as those associated with the conventional rheometer (up to $1000 \mathrm{~s}^{-1}$ ). It is therefore expected that it is the operating frequency and not the shear rate that affects the torsional probe measurements, and we investigate this here.

Non-Newtonian liquids under dynamic conditions can behave viscoelastically, the elastic contribution appearing through a complex and frequency dependent shear viscosity. The simplest theoretical formulation for such a material is the Maxwell model [23] consisting of a series 
combination of a single viscous element and a single elastic element, giving a Debye-type relaxation in the system from which the frequency dependence of viscosity is

$$
\eta=\frac{\eta_{s}}{\left(1+\omega^{2} \tau^{2}\right)}
$$

where $\tau$ is the relaxation time and $\eta_{\mathrm{s}}$ is the asymptotic low frequency viscosity.

For Newtonian fluids the characteristic relaxation time is significantly shorter than the period of the torsional oscillation, so that the measured viscosity remains relatively constant over a wide frequency interval. However, for the automotive and silicone oils measured in our study, the relaxation times are likely to be much longer and the corresponding relaxation frequency will be commensurable with the torsional probe frequency; the viscosity will fall as frequency increases. It is also worth noting that entanglements between molecules increase the steady flow viscosity significantly, whereas they have little effect on dynamic viscosity at relatively high frequencies. Eq. (13) is the simplest model for the frequency-dependent viscosity of a viscoelastic fluid. Fig. 16 shows that this model does not predict the complex behaviour of the oils we have used, and those studied by Shepard et al. [7]. Since these are long chain polymers it is appropriate to consider more complex models which account for, inter alia, distributions in molecular weight. A classic example here is the formulation of Barlow et al [19], which we have employed in this study.

Barlow's model considers the contribution of the many relaxation times occurring in a longchain polymer, by summing over segments of differing lengths, resulting in a broad frequency response overall. For a mono-disperse polymer liquid, the polymer chain can be divided into $N$ equal segments each consisting of $q$ monomer units, giving a viscosity [19]: 
$\eta=n k T \sum_{p=1}^{N} \frac{\tau_{p}}{1+\omega^{2} \tau_{p}^{2}}$

where, $n$ is the number of polymer molecules per volume and $k$ is Boltzmann's constant. The term $n k T$ can be replaced by $\rho_{\text {sol }} R T / \overline{M_{w}}$, where $\rho_{\text {sol }}$ is the solution density, $\overline{M_{w}}$ is the weightaverage molecular weight, $R$ is the gas constant and $T$ absolute temperature. The summation commences with $p=1$, corresponding to the whole molecule and continues up to $p=N$ representing the shortest segment. The relaxation times reduce as the segments get shorter. Use of the Rouse distribution for relaxation [24] gives relaxation times $\tau_{p}$ of the $p$ th mode of motion as

$$
\tau_{P}=\frac{\tau^{\prime}}{p^{2}}
$$

where, $\tau^{\prime}$ is the effective relaxation time of the molecule, given by:

$$
\tau^{\prime}=\frac{3 \eta_{s} \overline{M_{n}}}{\pi^{2} \rho_{\text {sol }} R T}
$$

where $\overline{M_{n}}$ is the number average molecular weight, defined by Barlow et al. [19] as $\overline{M_{w}}=2 \overline{M_{n}}$. Thus,

$$
\eta=\frac{6 \eta_{s}}{\pi^{2}} \sum_{p=1}^{N} \frac{1}{p^{2}+\omega^{2} \frac{\tau^{\prime 2}}{p^{2}}}
$$

We have used this equation to calculate the expected frequency dependence for the viscosity of the silicone oils measured in our study. The static viscosity in the equation was taken to be that measured using the conventional rheometer (Table 4). Since the molecular weight distribution of the silicone oils used in our measurements were not disclosed by the manufacturer and we were 
unable to obtain them, we applied a least-square fitting procedure for the number average molecular weight in eqs. (16-17), fitting the theoretical curve to the measured viscosity over the operating frequency range. The summation was carried out using $N=1000$. The fitted results for the frequency dependent viscosity for the three silicone oils are compared with the experimental measurements using the torsional probe in Fig. 17, and the results for the fitted molecular weights are shown in Table 5. The results show excellent agreement between the model predictions, constrained by the measured steady-shear viscosity, and the experimental viscosity measurements with the torsional probe. The figure demonstrates that the torsional probe measurements are consistent with the steady-state rheometer measurements for these oils, but that the significant reduction in viscosity is due to viscoelastic relaxation effects in the polymer molecules. The fitted molecular weights (Table 5) are very similar to those quoted by Barlow et al. [19], within an acceptable variation between samples.

\section{EXPERIMENTAL RESULTS: SLURRIES}

A similar set of experiments were performed on two sample slurries, identified at the bottom of Table 2 . The viscosity data obtained with the conventional rheometer was extremely variable due to the presence of large particles in the viscometer cup region. Figs. 18 and 19 illustrate these measurements for water-based and glycerol-based slurries at a shear rate of $50 \mathrm{~s}^{-1}$ over a period of 3 minutes. The viscosity values we have used were averages of the data taken at the longer times where the data appeared to be more stable.

The two slurry samples were also tested using the torsional waveguide probe with the same protocol as for the Newtonian liquids. The average viscosities measured over the range of frequencies are shown in Table 6 for each sample.

The results obtained from the torsional waveguide probe are several orders of magnitude lower than the values obtained by conventional rheometer, although these latter are not regarded as 
reliable. It is likely that the low readings from the waveguide probe resulted from the fact that the viscosity wave propagation distance in the liquid surrounding the rod was small in relation to the inter-particle spacing. Hence, the probe is more sensitive to the continuous phase rather than the whole mixture. Similar behaviour of a torsional probe used on slurries has been reported previously by Shepard et al. [7].

\section{DISCUSSION}

The first part of this paper dealt with factors influencing the design of a torsional waveguide viscosity probe. It was shown that measurement of guided wave attenuation rather than propagation velocity was to be preferred as errors in viscosity estimation were likely to be smaller. The principal design factors were the range of viscosities to be measured and the probe sensitivity to these, taking account of the limits to the range of attenuation that is measurable. The probe sensitivity depends on the material from which it is made, its diameter, the depth to which it is immersed in the test liquid (the gauge length), and the operating frequency. The effects of all of these variables on probe operation can be analysed through eqs. (3) and (10).

The large number of design variables implies that the process of design is likely to be iterative the question is where to start. In a conventional engineering context there will be constraints that may both guide and limit the design. Notwithstanding cost, the principal of these is likely to be probe length. The limits on measurable loss then translate into a range of attenuation coefficients for a given probe length. The operating frequency will be constrained to some extent by the availability of appropriate piezoelectric shear plates. There is likely to be a preferred device, and this sets the range within which the operating frequency will fall. The range of attenuation coefficients and frequency thus established, and the viscosity range requirement, then provide the basis for exploring the effects of different probe materials and thicknesses, taking account of the necessity of avoiding longitudinal and flexural modes in the rod (Fig. 2). It is likely that several 
iterations will be required before a workable design is established, although there will remain the possibility that a given specification may not be achievable as might be the case when low viscosity values are to be measured using a very short probe.

We have reported anomalous behaviour in the measurement of the viscosity of various oils, as have previous authors, although without explanation. The viscosities of these materials when measured with the torsional wave probe appeared to be very much lower than the values obtained with a conventional rheometer. Whilst the operating frequency was high, the amplitude of the torsional wave was low and the resulting shear rate in the surrounding liquid was commensurable with that of the rheometer. The behaviour was thus likely to be the result of operating frequency on the intramolecular relaxation within the polymeric oils. The simple Maxwell model, eq. (13), did not match the experimental results. The more complex model of Barlow et al [19] provided for a distribution of relaxation times, each depending on the length of an intramolecular segment. This model gave good agreement with viscosities measured with the torsional probe over the frequency band available for measurement $-525 \mathrm{kHz}$ to $725 \mathrm{kHz}$. Whilst this range of frequencies was quite narrow, it covered a region in which the viscosities of two of the oils were changing quite rapidly with frequency. We regard this as conclusive evidence that the anomalous results reported in this paper and by previous authors were the result of intramolecular relaxations in the oils.

In the case of slurries the viscosities measured by the guided wave probe were several orders of magnitude lower than those obtained by conventional rheometer, although data from the latter were quite variant due to the presence of particles between the rotating elements. It is likely that the low values were closer to the continuous phase because the inter-particle spacing in the slurry was significantly greater than the propagation distance of the viscosity wave in the continuous phase, which is of the order of one wavelength. 


\section{CONCLUSIONS}

The factors influencing the design of a torsional waveguide viscosity probe have been established and a prototype device was shown to work well when applied to Newtonian fluids. Lower than expected viscosities were measured in polymeric fluids whose behaviour was nonNewtonian, and this effect has been explained on the basis of intramolecular relaxations. The probe was not sensitive to the viscosity of bulk slurries, and this will form the subject of a future publication.

\section{REFERENCES}

[1] J. O. Kim and H. H. Bau, "On line, Real-Time Densimeter - Theory and Optimization," Journal of the Acoustical Society of America, vol. 85, no. 1, pp. 432-439, 1989.

[2] J. O. Kim, H. H. Bau, Y. Liu, L. C. Lynnworth, S. A. Lynnworth, K. A. Hall, S. A. Jacobson, J. A. Korba, R. J. Murphy, M. A. Strauch and K. G. King, "Torsional Sensor Applications in Two-Phase Fluids," IEEE Transactions on Ultrasonics Ferroelectrics and Frequency Control, vol. 40, no. 5, pp. 563-576, 1993.

[3] J. O. Kim, Y. Z. Wang and H. H. Bau, "The Effect of an Adjacent Viscouse-Fluid on the Transmission of Torsional Stress Waves in a Submerged Wave-Guide," Journal of the Acoustical Society of America, vol. 89, no. 3, pp. 1414-1422, 1991.

[4] J. O. Kim and H. H. Bau, "Instrument for Simultaneous Measurement of Density and Viscosity," Review of Scientific Instruments, vol. 60, no. 6, pp. 1111-1115, 1989.

[5] R. D. Costley, G. Boudreaux, K. Balasubramaniam and J. A. Simpson, "Waveguide Sensor for Liquid and Slurry Properties," in Review of Progress in Quantitative Nondestructive 
Evaluation, vol. 18, D. O. Thompson and D. E. Chimenti, Eds. New York:Plenum, 1999, pp. 1171-1175.

[6] R. D. Costley, K. Balasubramaniam, W. M. Ingham, J. A. Simpson and V. Shah, "Torsional Waveguide Sensor for Molten Materials," in Review of Progress in Quantitative Nondestructive Evaluation, vol. 17, D. O. Thompson and D. E. Chimenti, Eds. New York:Plenum, 1998, pp. 859-866.

[7] C. L. Shepard, Burghard, B.J., L. A. Friesel, B. P. Hildebrand, M. Xang, A. A. Diaz and C. W. Enderlin, "Measurements of Density and Viscosity of One- and Two-Phase Fluids with Torsional Waveguides," IEEE Transactions on Ultrasonics Ferroelectrics and Frequency Control, vol. 46, no. 3, pp. 536-548, 1999.

[8] T. K. Vogt, M. J. S. Lowe and P. Cawley, "Measurement of the Material Properties of Viscous Liquids Using Ultrasonic Guided Waves," IEEE Transactions on Ultrasonics Ferroelectrics and Frequency Control, vol. 51, no. 6, pp. 737-747, 2004.

[9] Y. H. Ai and R. A. Lange, "Theoretical Analyses and Numerical Simulations of the Torsional Mode for Two Acoustic Viscometers with Preliminary Experimental Tests," IEEE Transactions on Ultrasonics Ferroelectrics and Frequency Control, vol. 55, no. 3, pp. 648-658, 2008.

[10] B. Pavlakovic,M. J. S. Lowe, D. Alleyne and P. Cawley, "Disperse: A General Purpose Program for Creating Dispersion Curves," in Review of Progress in Quantitative NondestructiveEvaluation, vol. 16, D. O. Thompson and D. E. Chimenti, Eds. New York:Plenum, 1997, pp. 185-192.

[11] M. G. Silk and K. F. Bainton, "Propagation in Metal Tubing of Ultrasonic Wave Modes Equivalent to Lamb Waves," Ultrasonics, vol. 17, no. 1, pp. 11-19, 1979. 
[12] Cannon Instrument Company, State College, PA, USA.

[13] Brookfield Engineering Laboratories Inc., Middleboro, Massachusetts, USA.

[14] A. N. Kalashnikov and R. E. Challis, "Errors and Uncertainties in the Measurement of Ultrasonic Wave Attenuation and Phase Velocity," IEEE Transactions on Ultrasonics Ferroelectrics and Frequency Control, vol. 52, no. 10, pp. 1754-1768, 2005.

[15] L. Cohen, "Time-Frequency Distributions - A Review," Proceedings of the IEEE, vol. 77, no. 7, pp. 941-981, 1989.

[16] W. H. Prosser, M. D. Seale and B. T. Smith, "Time-Frequency Analysis of the Dispersion of Lamb Modes," Journal of the Acoustical Society of America, vol. 105, no. 5, pp. 26692676, 1999.

[17] M. Niethammer, L. J. Jacobs, J. M. Qu and J. Jarzynski, "Time-Frequency Representations of Lamb Waves," Journal of the Acoustical Society of America, vol. 109, no. 5, pp. 18411847, 2001.

[18] F. B. Cegla, P. Cawley, and M. J. S. Lowe, "Material property measurement using the quasi-Scholtemode_-A waveguide sensor," Journal of the Acoustical Society of America, vol. 117, no. 3, pp. 1098-1107, 2005.

[19] A. J. Barlow, G. Harrison and J. Lamb, "Viscoelastic Relaxation of Polydimethylsiloxane Liquids," Proceedings of the Royal Society of London Series A-Mathematical and Physical Sciences, vol. 282, no. 1388, pp. 228-251, 1964.

[20] J. L. Hunter and P. R. Derdul, "Acoustic Absorption and Dynamic Viscosity in a LongChain Polymer," Journal of the Acoustical Society of America, vol. 42, no. 5, pp. 10411044, 1967. 
[21] C. Verdier, P. Y. Longin and M. Piau, "Dynamic Shear and Compressional Behavior of Polydimethylsiloxanes: Ultrasonic and Low Frequency Characterization," Rheologica Acta, vol. 37, no. 3, pp. 234-244, 1998.

[22] A. I. Romoscanu, M. B. Sayir, K. Hausler and C. Servais, "High Frequency Probe for the Measurement of the Complex Viscosity of Liquids," Measurement Science \& Technology, vol. 14, no. 4, pp. 451-462, 2003.

[23] J. C. Maxwell, "On the Dynamical Theory of Gases," Philosophical Transactions of the Royal Society of London, vol. 157, pp. 49-87, 1867.

[24] P. E. Rouse, "A Theory of the Linear Viscoelastic Properties of Dilute Solutions of Coiling Polymers," Journal of Chemical Physics, vol. 21, no. 7, pp. 1272-1280, 1953.

[25] D. R. Lide, CRC Handbook of Chemistry and Physics, 85th ed. Boca Raton: CRC Press, 2004.

[26] G. W. C. Kaye and T. H. Laby, Kaye \& Laby Tables of Physical and Chemical Constants, 16th ed. Harlow: Longman, 1995.

[27] Staff of Research Education Association, Handbook of Mathematical, Scientific, and Engineering Formulas: Tables, Functions, Graphs, Transforms, New Jersey: Research \& Education Association, 2001.

[28] Dow Corning Corporation, Midland, MI, USA. 


\section{TABLES}

\begin{tabular}{|lll|}
\hline Material & Density $\left(\mathrm{kgm}^{-3}\right)$ & Shear Modulus (GPa) \\
\hline Aluminium & $2697.0^{\mathrm{a}}$ & $26.1^{\mathrm{b}}$ \\
Brass & $8400.0^{\mathrm{b}}$ & $37.3^{\mathrm{b}}$ \\
Phosphor bronze & $8900.0^{\mathrm{b}}$ & $41.4^{\mathrm{c}}$ \\
Nickel silver & $8800.0^{\mathrm{b}}$ & $49.7^{\mathrm{b}}$ \\
Copper & $8932.0^{\mathrm{a}}$ & $48.3^{\mathrm{b}}$ \\
Carbon steel/Mild steel & $7868.8^{\mathrm{d}}$ & $79.5^{\mathrm{d}}$ \\
Iron & $7867.2^{\mathrm{a}}$ & $81.6^{\mathrm{b}}$ \\
Nickel & $8910.0^{\mathrm{a}}$ & $76.0^{\mathrm{b}}$ \\
\hline
\end{tabular}

Table 1. Metals used for Fig. 5.
a. Ref. [25] CRC Handbook of Chemistry and Physics (2004).
b. Ref. [26] Kaye \& Laby (1995).
c. Ref. [27] Handbook of Mathematical, Scientific, and Engineering Formulas (2001).
d. Measured in our laboratory. 


\begin{tabular}{|ll|}
\hline Water & Distilled water \\
Olive oil & Extra virgin olive oil \\
Sunflower oil & Sunflower \\
Golden syrup water solution & 80\% golden syrup (by volume) \\
Golden syrup water solution & 81.5\% golden syrup (by volume) \\
Glycerol water solution & $94 \%$ glycerol (by volume) \\
Glycerol water solution & $96 \%$ glycerol (by volume) \\
Castor oil & Castor oil 100\% pure \\
Engine oil & Mobil, Fully synthetic motor oil, SAE 5W-30 \\
Engine oil & Mobil, Fully synthetic motor oil, SAE 5W-40 \\
Engine oil & Mobil, Fully synthetic motor oil, SAE 5W-50 \\
Engine oil & Castrol, Fully synthetic motor oil with di-ester, SAE 10W-60 \\
Gear oil & Gulf Gear TX , Automotive gear oil, SAE 75W-80 \\
Silicone fluid & Dow corning 200 silicone fluid, viscosity 100 Centistokes \\
Silicone fluid & Dow corning 200 silicone fluid, viscosity 350 Centistokes \\
Silicone fluid & Dow corning 200 silicone fluid, viscosity 1000 Centistokes \\
Slurry 1 (water based) & 2:1 DS1: Versamag \\
\hline
\end{tabular}

Table 2. Liquids used for viscosity measurements. 


\begin{tabular}{|lccl|}
\hline Testing Medium & Density $\left(\mathrm{kgm}^{-3}\right)$ & Viscosity (Pa.s) & Viscosity (Pa.s) \\
& & Physica MCR 301 & Torsional probe \\
\hline Distilled water & 996.9 & 0.0009 & 0.0012 \\
Sunflower oil & 913.0 & 0.0565 & 0.0557 \\
Olive oil & 907.9 & 0.0717 & 0.0710 \\
Golden syrup 80\% & 1343.5 & 0.1900 & 0.1761 \\
Golden syrup 81.5\% & 1349.0 & 0.2494 & 0.2284 \\
Glycerol 94\% & 1257.0 & 0.4359 & 0.4099 \\
Glycerol 96\% & 1261.0 & 0.6088 & 0.6196 \\
Castor oil & 969.0 & 0.9230 & 0.8617 \\
\hline
\end{tabular}

Table 3. Densities and viscosities of the Newtonian liquids.

\begin{tabular}{|llll|}
\hline Testing Medium & Density $\left(\mathrm{kgm}^{-3}\right)$ & Viscosity (Pa.s) & Viscosity (Pa.s) \\
& & Physica MCR 301 & Torsional probe \\
\hline Silicone fluid 100 cSt & 956.0 & 0.1041 & 0.0977 \\
Silicone fluid 350 cSt & 973.0 & 0.3866 & 0.1655 \\
Silicone fluid 1000 cSt & 975.0 & 1.0580 & 0.1828 \\
Engine oil 5W-30 & 847.0 & 0.1498 & 0.0934 \\
Engine oil 5W-40 & 847.0 & 0.1796 & 0.0764 \\
Engine oil 5W-50 & 851.5 & 0.2350 & 0.0945 \\
Engine oil 10W-60 & 853.0 & 0.3950 & 0.1361 \\
Gear oil 75W-80 & 884.0 & 0.1632 & 0.1284 \\
\hline
\end{tabular}

Table 4. Densities and viscosities of the non-Newtonian liquids. Torsional probe measurements are at $625 \mathrm{kHz}$. 


\begin{tabular}{|lll|}
\hline Viscosity grade (cSt) & Number-average molecular & Number-average molecular \\
& weight $\left(\mathrm{kgmol}^{-1}\right)$, from [19]. & $\begin{array}{l}\text { weight }\left(\mathrm{kgmol}^{-1}\right) \text {, from } \\
\text { experiments. }\end{array}$ \\
\hline 100 & 6.3 & 5.97 \\
350 & 15.8 & 12.84 \\
1000 & 21.0 & 29.08 \\
\hline
\end{tabular}

Table 5. Number average molecular weight for 100, 350 and 1000 cSt silicone fluids [28].

\begin{tabular}{|llll|}
\hline Testing Medium & Density $\left(\mathrm{kgm}^{-3}\right)$ & Viscosity (Pa.s) & Viscosity (Pa.s) \\
& & Physica MCR 301 & Torsional probe \\
\hline Slurry 1 (water based) & 1358.0 & $\sim 5$ & 0.0042 \\
Slurry 2 (glycerol based) & 1581.0 & $\sim 12$ & 0.4904 \\
\hline
\end{tabular}

Table 6. Densities and viscosities of the slurries. 


\section{CAPTIONS TO FIGURES}

Fig. 1. Operating principle of the guided wave probe

Fig. 2. Dispersion curves for cylindrical carbon steel rods: Group velocity versus frequencydiameter product. $\mathrm{T}(0,1)$ dashed line, $\mathrm{L}(0,1)$ dotted line and $\mathrm{F}(1,1)$ dash-dot line, higher $\mathrm{L}$ and $\mathrm{F}$ modes solid lines.

Fig. 3. Relative attenuation error as function of viscosity for $1 \%$ percent relative error in viscosity for a $1 \mathrm{~mm}$ diameter carbon steel rod embedded in a liquid of density $913 \mathrm{kgm}^{-1}$. Each line represents a single frequency in the range $50 \mathrm{kHz}$ (top) to $800 \mathrm{kHz}$ (bottom) in steps of 150 $\mathrm{kHz}$.

Fig. 4. Relative velocity error as function of viscosity for $1 \%$ percent relative error in viscosity for a $1 \mathrm{~mm}$ diameter carbon steel rod embedded in a liquid of density $913 \mathrm{kgm}^{-1}$. Each line represents a single frequency in the range $50 \mathrm{kHz}$ (top) to $800 \mathrm{kHz}$ (bottom) in steps of $150 \mathrm{kHz}$.

Fig. 5. Attenuation of $\mathrm{T}(0,1)$ mode at $600 \mathrm{kHz}$ versus viscosity for a $1 \mathrm{~mm}$ diameter waveguide made of different materials immersed in a liquid of density $913 \mathrm{kgm}^{-3}$. The materials are, left to right: aluminium, brass, phosphor bronze, nickel silver, copper, carbon steel/mild steel, iron, nickel.

Fig. 6. Attenuation at $600 \mathrm{kHz}$ versus viscosity for carbon steel rods with diameters $1 \mathrm{~mm}$ (solid), $2 \mathrm{~mm}$ (dotted) and $3 \mathrm{~mm}$ (dashed).

Fig. 7. Attenuation versus viscosity for a $1 \mathrm{~mm}$ diameter carbon steel rod at frequencies $200 \mathrm{kHz}$ (dashed), $400 \mathrm{kHz}$ (dotted) and $600 \mathrm{kHz}$ (solid).

Fig. 8. Torsional wave probes of diameters $1 \mathrm{~mm}$ to $6 \mathrm{~mm}$ in steps of $1 \mathrm{~mm}$. 
Fig. 9. Schematic of the arrangement to excite the $T(0,1)$ mode using piezoelectric shear plates bonded to the probe rod.

Fig. 10. Time-frequency spectrogram of excited modes in the $1.0 \mathrm{~mm}$ diameter carbon steel rod in vacuo showing the predicted modes (solid, dotted-dash and dashed lines). The colour scale is calibrated in $\mathrm{dB}$.

Fig. 11. Time-frequency spectrogram of excited modes in the $1.0 \mathrm{~mm}$ diameter carbon steel rod when immersed in water showing the predicted modes (solid and dashed lines).

Fig. 12. Measured attenuation in $1 \mathrm{~mm}$ diameter carbon steel rod embedded in an $80 \%$ golden syrup in water solution ( $\mathbf{a})$ versus frequency, superimposed on the curve predicted from eq. (3).

Fig. 13. Experimental arrangement.

Fig. 14. Newtonian liquids: Comparison of viscosities measured by conventional rheometer and the torsional waveguide probe.

Fig. 15. Non-Newtonian liquids: Comparison of viscosities measured by conventional rheometer and the torsional waveguide probe.

Fig. 16. Viscosity measurements on 100, 350 and 100 cSt grade silicone oils using the torsional probe (symbols) superimposed on a curve predicted by the single relaxation time Maxwell model [23], eq. (13).

Fig. 17. Viscosity measurements on 100, 350 and 100 cSt grade silicone oils using the torsional probe (symbols) superimposed on a curve predicted by the model of Barlow et al. [19], eq. (17).

Fig. 18. Two conventional rheometer measurements of viscosity versus time for the water-based slurry at shear rate $50 \mathrm{~s}^{-1}$. 
Fig. 19. Two conventional rheometer measurements of viscosity versus time for the glycerolbased slurry at shear rate $50 \mathrm{~s}^{-1}$. 


\section{FIGURES}

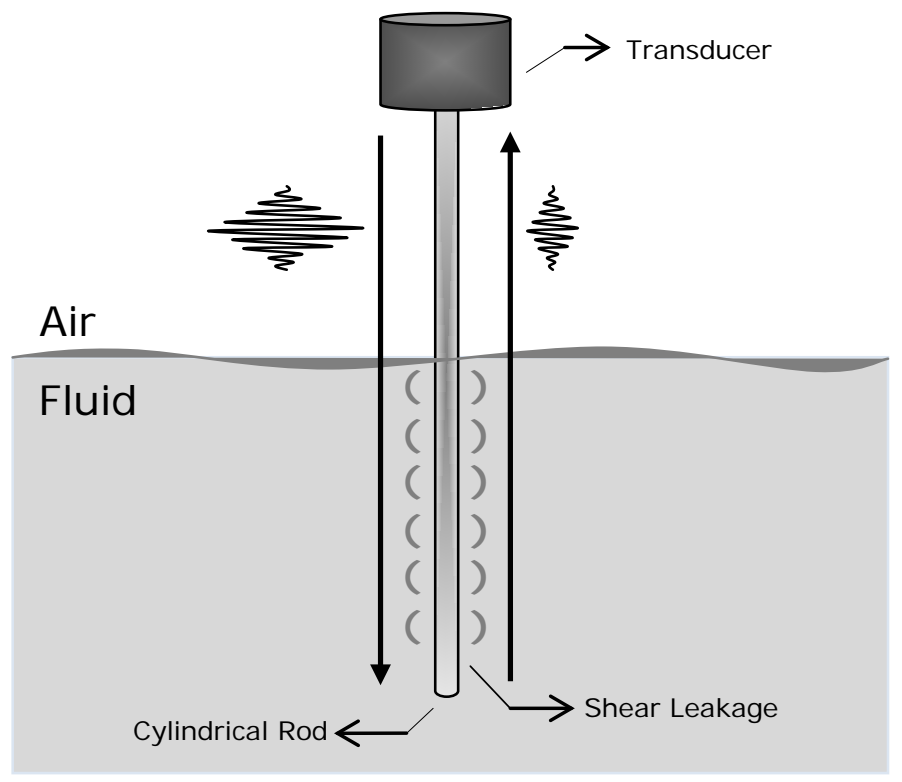

Fig. 1. Operating principle of the guided wave probe.

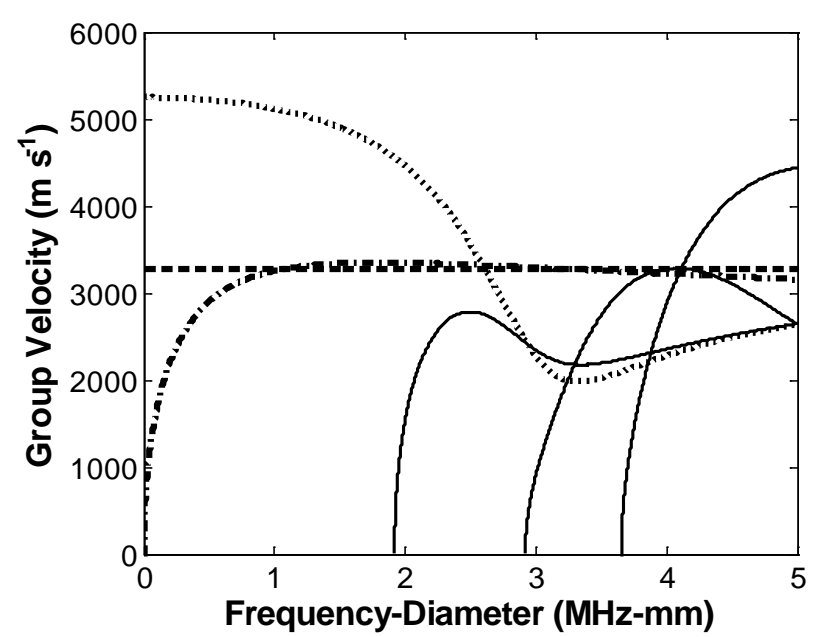

Fig. 2. Dispersion curves for cylindrical carbon steel rods: Group velocity versus frequencydiameter product. $\mathrm{T}(0,1)$ dashed line, $\mathrm{L}(0,1)$ dotted line and $\mathrm{F}(1,1)$ dash-dot line, higher $\mathrm{L}$ and $\mathrm{F}$ modes solid lines. 


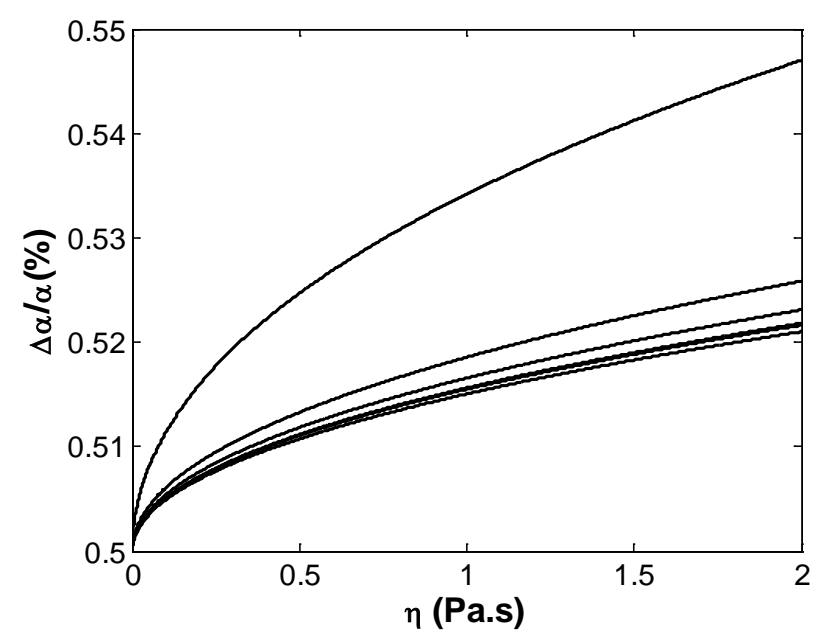

Fig. 3. Relative attenuation error as function of viscosity for $1 \%$ percent relative error in viscosity for a $1 \mathrm{~mm}$ diameter carbon steel rod embedded in a liquid of density $913 \mathrm{kgm}^{-1}$. Each line represents a single frequency in the range $50 \mathrm{kHz}$ (top) to $800 \mathrm{kHz}$ (bottom) in steps of 150 kHz.

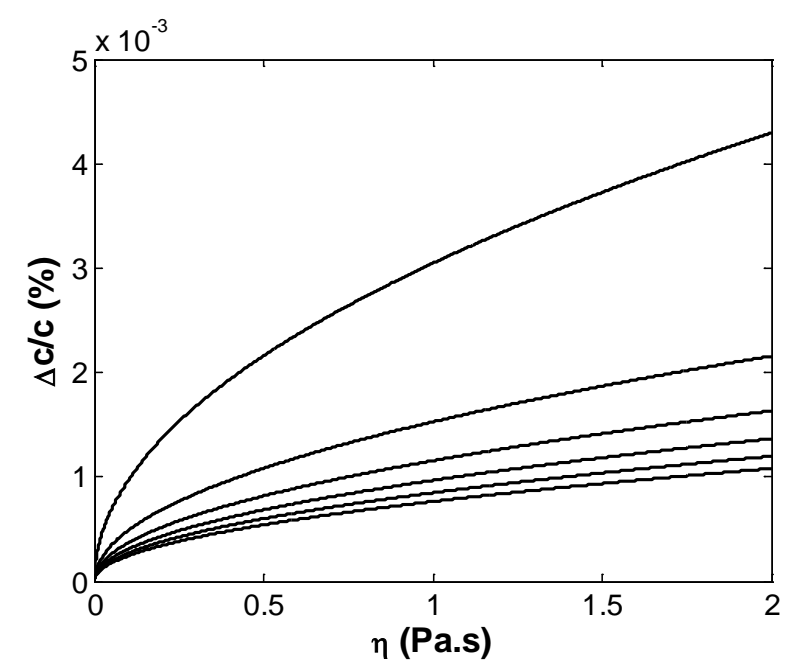

Fig. 4. Relative velocity error as function of viscosity for $1 \%$ percent relative error in viscosity for a $1 \mathrm{~mm}$ diameter carbon steel rod embedded in a liquid of density $913 \mathrm{kgm}^{-1}$. Each line represents a single frequency in the range $50 \mathrm{kHz}$ (top) to $800 \mathrm{kHz}$ (bottom) in steps of $150 \mathrm{kHz}$. 


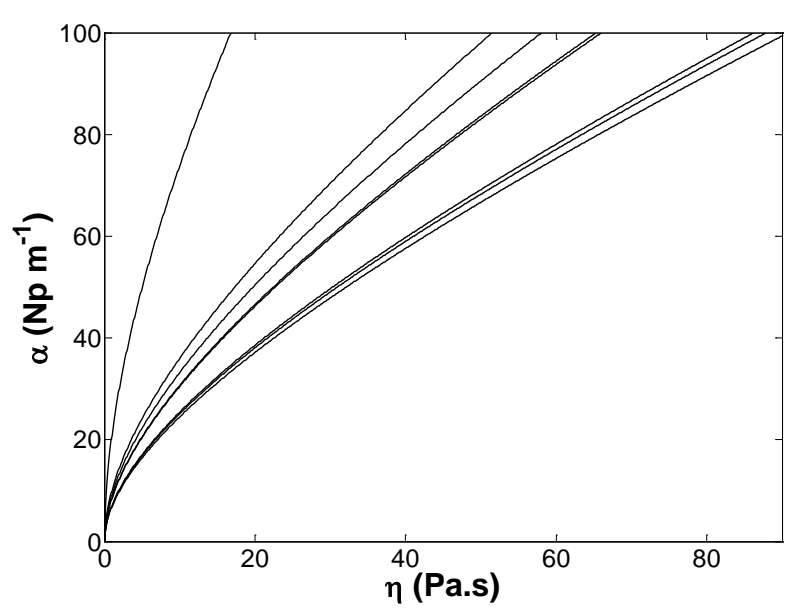

Fig. 5. Attenuation of $\mathrm{T}(0,1)$ mode at $600 \mathrm{kHz}$ versus viscosity for a $1 \mathrm{~mm}$ diameter waveguide made of different materials immersed in a liquid of density $913 \mathrm{kgm}^{-3}$. The materials are, left to right: aluminium, brass, phosphor bronze, nickel silver, copper, carbon steel/mild steel, iron, nickel.

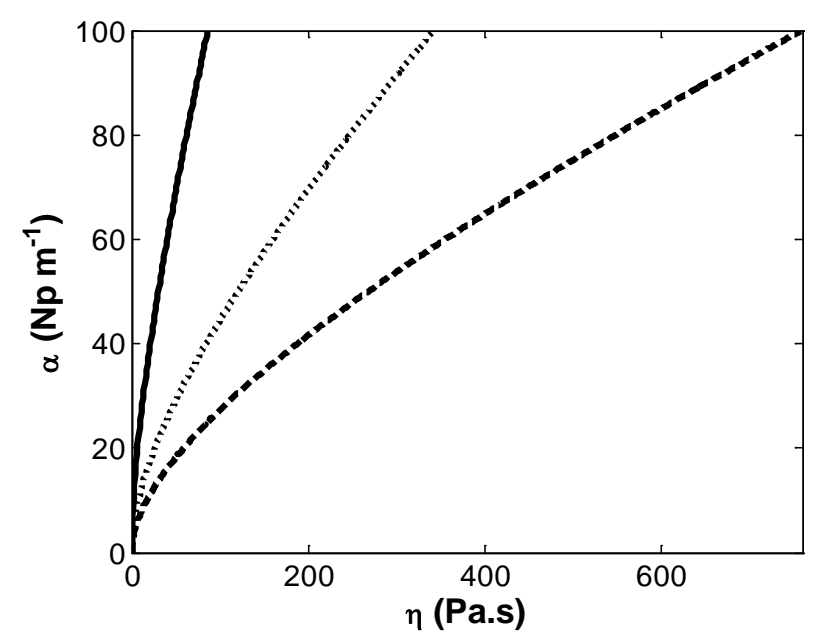

Fig. 6. Attenuation at $600 \mathrm{kHz}$ versus viscosity for carbon steel rods with diameters $1 \mathrm{~mm}$ (solid), $2 \mathrm{~mm}$ (dotted) and $3 \mathrm{~mm}$ (dashed). 


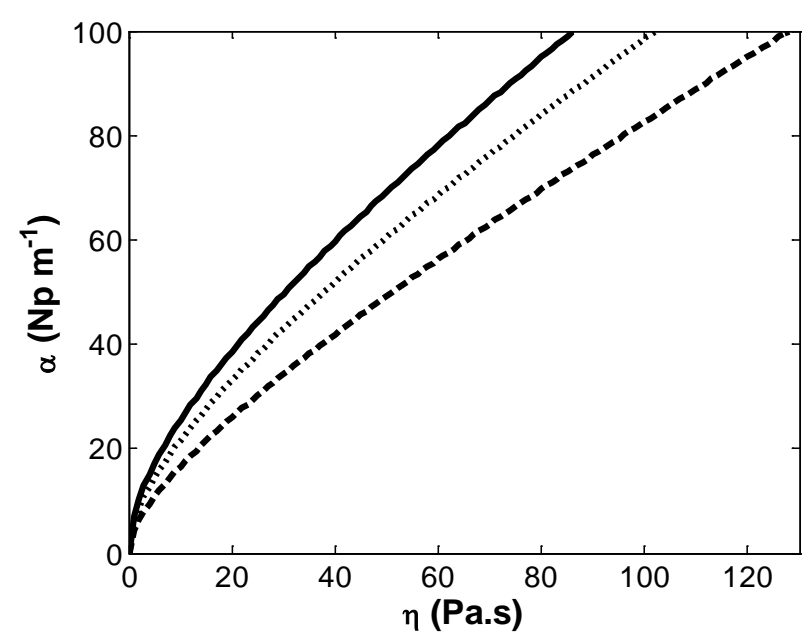

Fig. 7. Attenuation versus viscosity for a $1 \mathrm{~mm}$ diameter carbon steel rod at frequencies $200 \mathrm{kHz}$ (dashed), $400 \mathrm{kHz}$ (dotted) and $600 \mathrm{kHz}$ (solid).

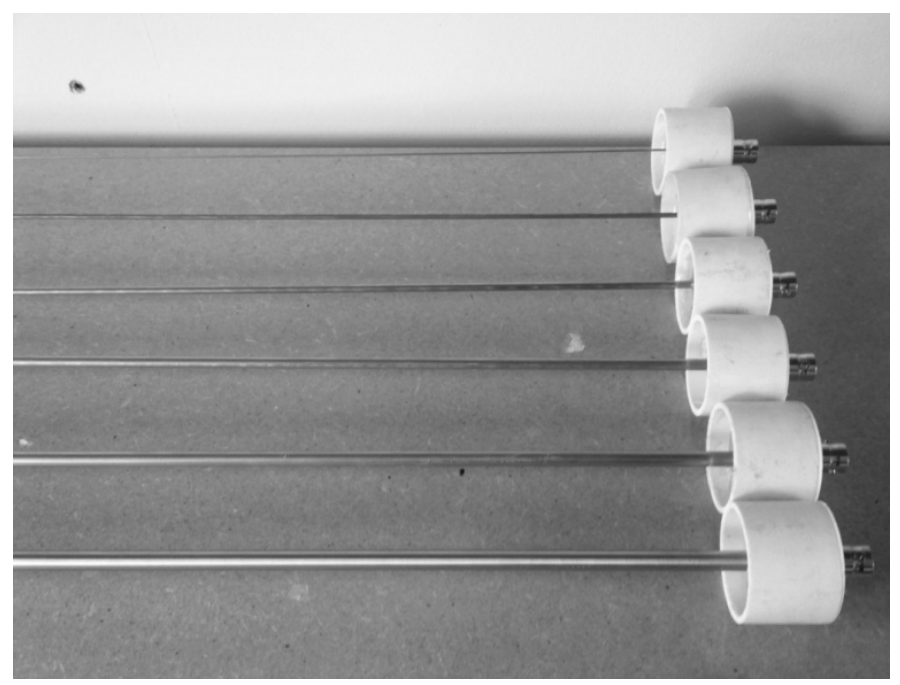

Fig. 8. Torsional wave probes of diameters $1 \mathrm{~mm}$ to $6 \mathrm{~mm}$ in steps of $1 \mathrm{~mm}$. 


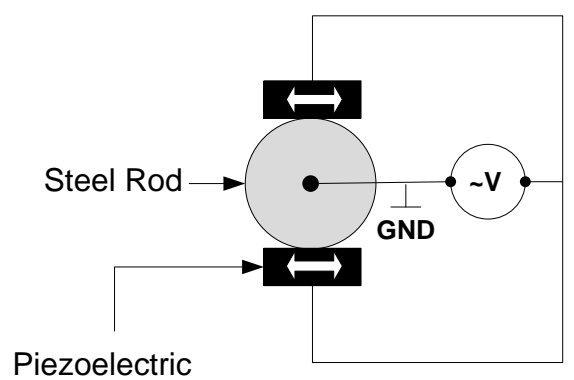

Shear Plate

Fig. 9. Schematic of the arrangement to excite the $T(0,1)$ mode using piezoelectric shear plates bonded to the probe rod.

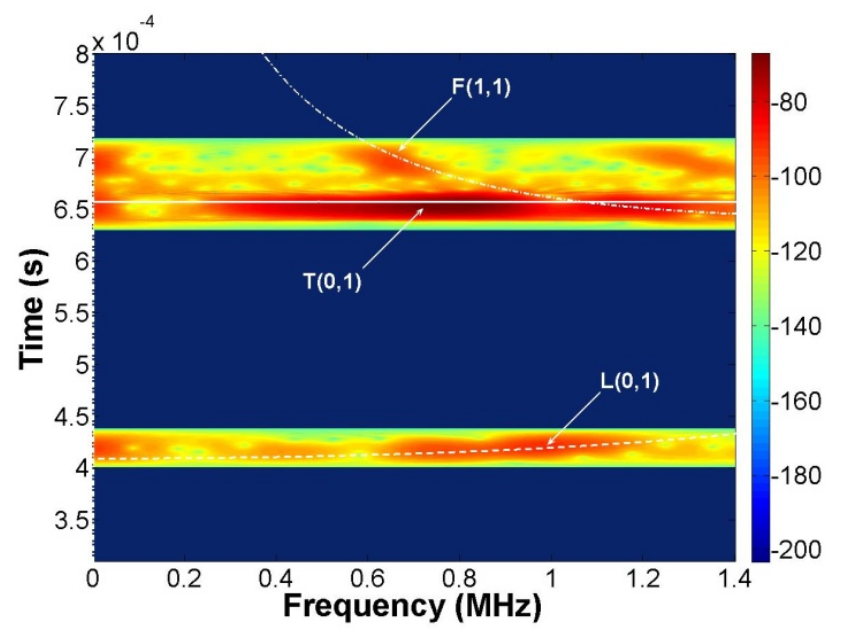

Fig. 10. Time-frequency spectrogram of excited modes in the $1.0 \mathrm{~mm}$ diameter carbon steel rod in vacuo showing the predicted modes (solid, dotted-dash and dashed lines). The colour scale is calibrated in $\mathrm{dB}$. 


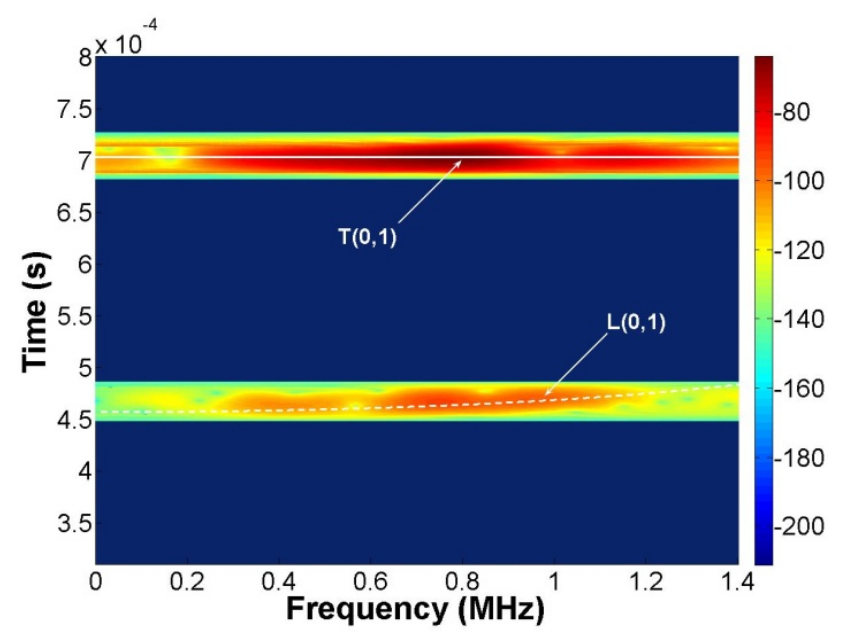

Fig. 11. Time-frequency spectrogram of excited modes in the $1.0 \mathrm{~mm}$ diameter carbon steel rod when immersed in water showing the predicted modes (solid and dashed lines).

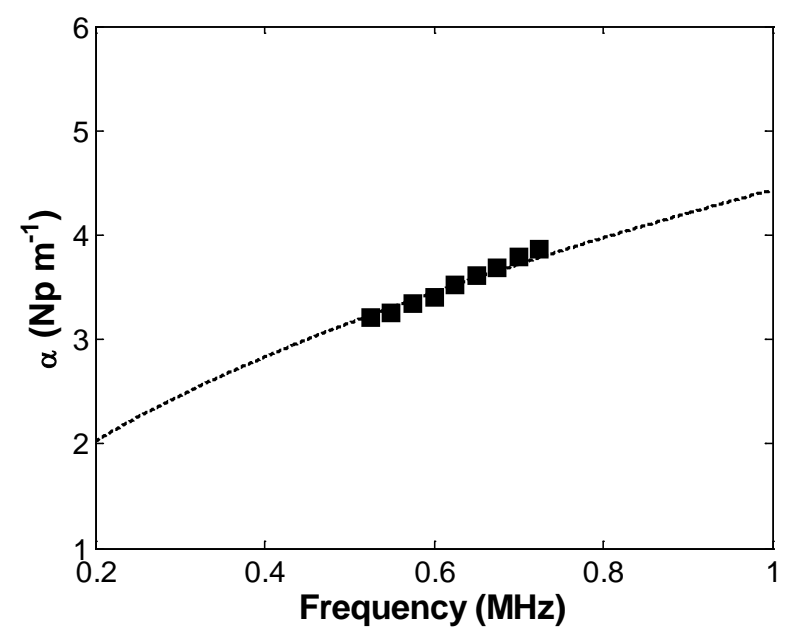

Fig. 12. Measured attenuation in $1 \mathrm{~mm}$ diameter carbon steel rod embedded in an $80 \%$ golden syrup in water solution ( $\mathbf{a})$ versus frequency, superimposed on the curve predicted from eq. (3). 


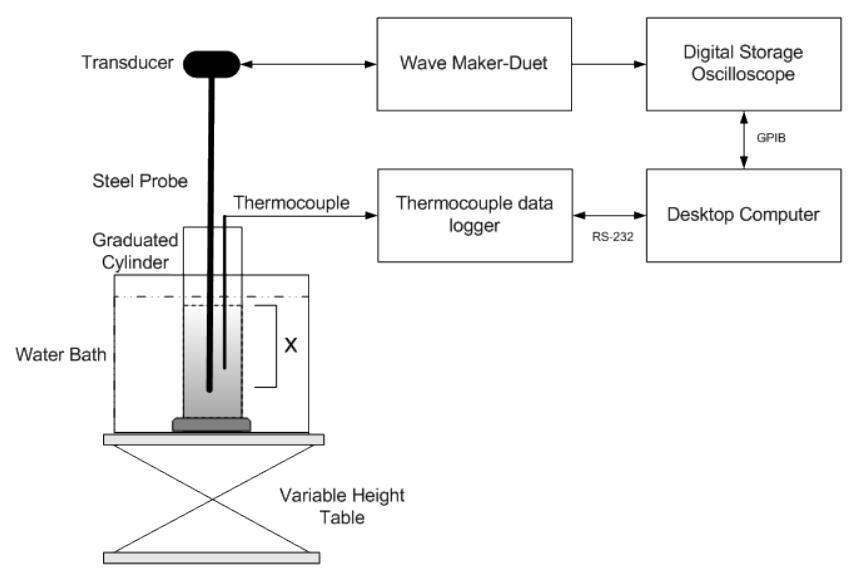

Fig. 13. Experimental arrangement.

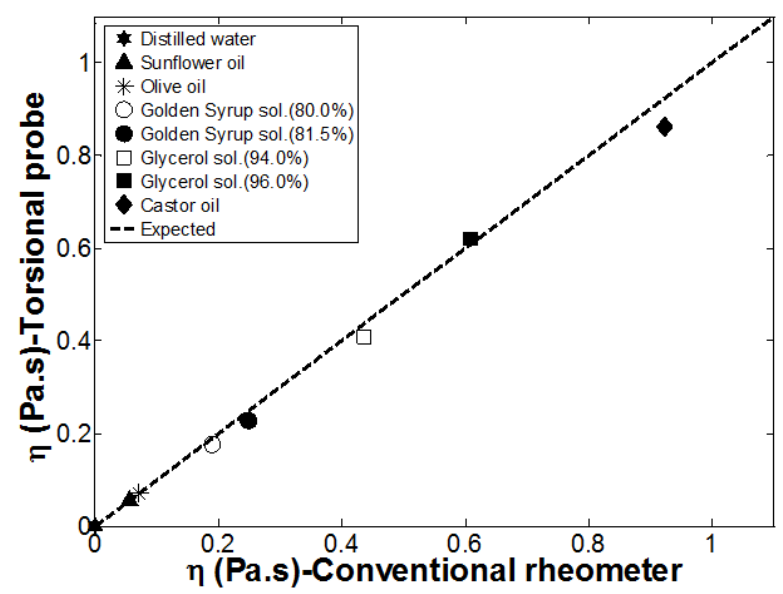

Fig. 14. Newtonian liquids: Comparison of viscosities measured by conventional rheometer and the torsional waveguide probe. 


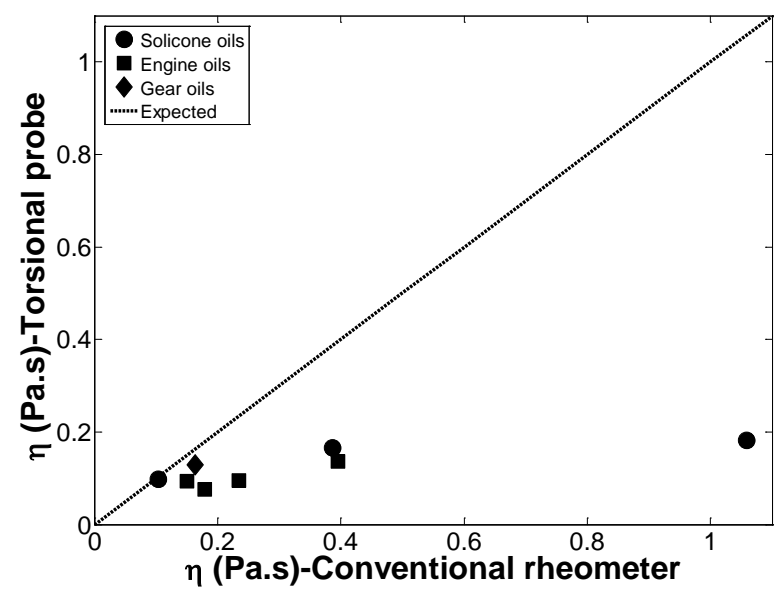

Fig. 15. Non-Newtonian liquids: Comparison of viscosities measured by conventional rheometer and the torsional waveguide probe.

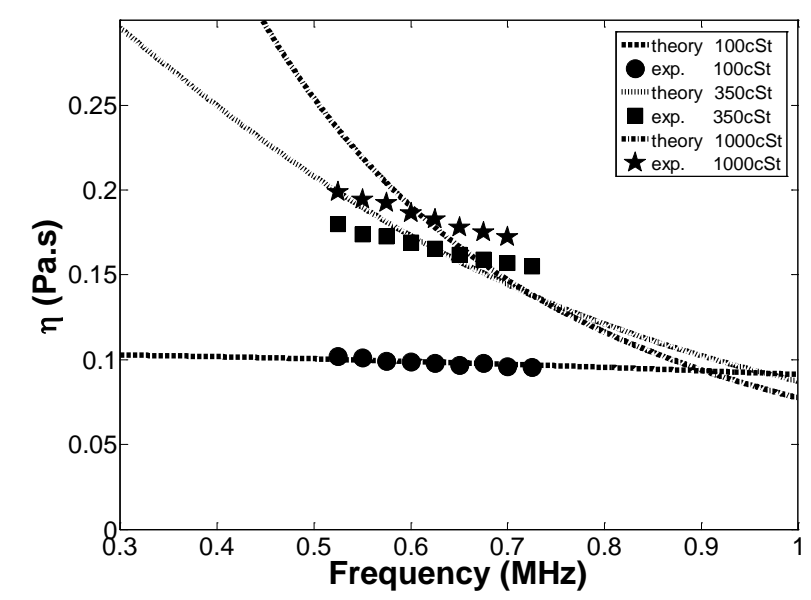

Fig. 16. Viscosity measurements on 100, 350 and 1000 cSt grade silicone oils using the torsional probe (symbols) superimposed on a curve predicted by the single relaxation time Maxwell model [22], eq. (13). 


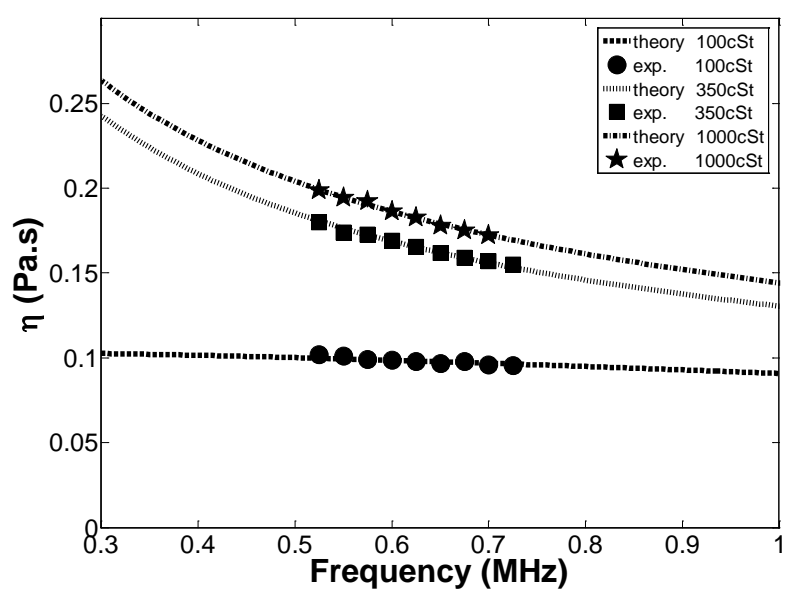

Fig. 17. Viscosity measurements on 100, 350 and 1000 cSt grade silicone oils using the torsional probe (symbols) superimposed on a curve predicted by the model of Barlow et al. [19], eq. (17).

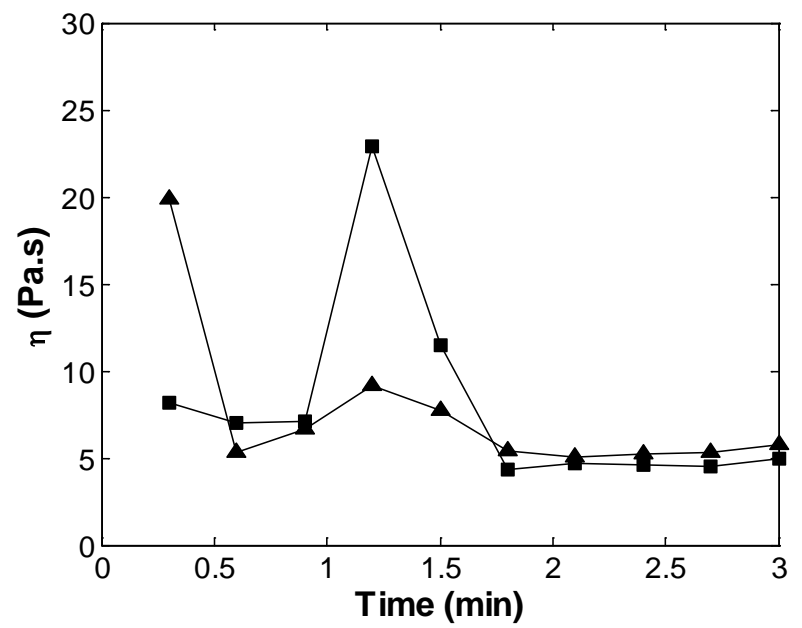

Fig. 18. Two conventional rheometer measurements of viscosity versus time for the water-based slurry at shear rate $50 \mathrm{~s}^{-1}$. 


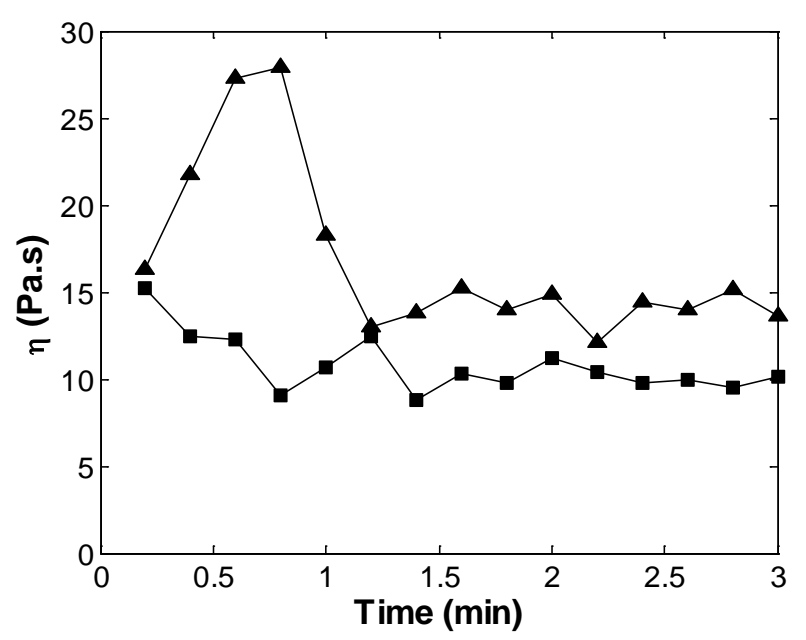

Fig. 19. Two conventional rheometer measurements of viscosity versus time for the glycerolbased slurry at shear rate $50 \mathrm{~s}^{-1}$. 